\title{
Use of case reports and the Adverse Event Reporting System in systematic reviews: overcoming barriers to assess the link between Crohn's disease medications and hepatosplenic T-cell lymphoma
}

Saranya A Selvaraj ${ }^{1,4^{*}}$, Elizabeth Chairez², Lisa M Wilson ${ }^{1}$, Mark Lazarev ${ }^{1}$, Eric B Bass ${ }^{1,3}$ and Susan Hutfless ${ }^{1 *}$

\begin{abstract}
Background: To identify demographic and clinical characteristics associated with cases of hepatosplenic T-cell lymphoma (HSTCL) in patients with Crohn's disease, and to assess strength of evidence for a causal relationship between medications and HSTCL in Crohn's disease.

Methods: We identified cases of HSTCL in Crohn's disease in studies included in a comparative effectiveness review of Crohn's disease medications, through a separate search of PubMed and Embase for published case reports, and from the Food and Drug Administration (FDA) Adverse Event Reporting System (AERS). We used three causality assessment tools to evaluate the relationship between medication exposure and HSTCL.

Results: We found 37 unique cases of HSTCL in patients with Crohn's disease. Six cases were unique to the published literature and nine were unique to AERS. Cases were typically young (<40 years of age) and male (86\%). The most commonly reported medications were anti-metabolites (97\%) and anti-tumor necrosis factor alpha (anti-TNFa) medications (76\%). Dose and duration of therapy were not consistently reported. Use of aminosalicylates and corticosteroids were rarely reported, despite the high prevalence of these medications in routine treatment. Using the causality assessment tools, it could only be determined that anti-metabolite and anti-TNFa therapies were possible causes of HSTCL in Crohn's disease based on the data contained in the case reports.

Conclusion: Systematic reviews that incorporate case reports of rare lethal events should search both published literature and AERS, but consideration should be given to the limitations of case reports. In this study, establishing a causative effect other than 'possible' between anti-metabolite or anti-TNFa therapies and HSTCL was not feasible because case reports lacked data required by the causality assessments, and because of the limited applicability of causality assessment tools for rare irreversible events. We recommend minimum reporting requirements for case reports to improve causality assessment and routine reporting of rare life-threatening events, including their absence, in clinical trials to help clinicians determine whether rare adverse events are causally related to a medication.
\end{abstract}

Keywords: Crohn's disease, Hepatosplenic T-cell lymphoma, Causality assessment, Adverse event reporting, Case reports, Systematic reviews

\footnotetext{
*Correspondence: sselvar1@jhmi.edu; shutfle1@jhmi.edu

'Johns Hopkins University School of Medicine, 733 North Broadway,

Baltimore, MD 21205-2196, USA

${ }^{4}$ University of Maryland Medical Center, 22 South Greene Street, Room

N3E09, Baltimore, MD 21201-1595, USA

Full list of author information is available at the end of the article
} 


\section{Background}

Crohn's disease is an idiopathic, chronic, inflammatory bowel disease that affects the gastrointestinal tract. An estimated 565,000 to 720,000 people in the United States have Crohn's disease [1]. In the 1950s, corticosteroids and sulfasalazine were adopted as the first immunosuppressive treatments for Crohn's disease, followed by the anti-metabolites, 6-mercaptopurine and azathioprine, in the 1960s [2]. The twenty-first century has brought with it the first biologic agent for Crohn's disease, infliximab, a monoclonal antibody against tumor necrosis factor alpha (anti-TNFa). Adalimumab and certolizumab pegol are the other approved anti-TNFa agents.

Hepatosplenic T-cell lymphoma (HSTCL) is a rare and often fatal outcome associated with Crohn's disease. A boxed warning was issued in 2006 for an association between infliximab and HSTCL. As of October 2011, the label for infliximab reads:

'Postmarketing cases of fatal hepatosplenic T-cell lymphoma (HSTCL) have been reported in patients treated with TNF blockers including infliximab. All infliximab cases were reported in patients with Crohn's disease or ulcerative colitis, the majority of whom were adolescent or young adult males. All had received azathioprine or 6-mercaptopurine concomitantly with infliximab at or prior to diagnosis (brand name changed to generic in italics)' [3].

Despite increasing concerns about the use of antiTNFa medications, there is no definitively established causal mechanism for HSTCL. Risk factors for HSTCL are thought to include young age, male gender, Crohn's disease, and renal transplantation [4]. However, HSTCL has occurred in the absence of immunosuppressive treatment and immunodeficiency [5]. Symptoms of HSTCL include fever, cytopenias, and an enlarged spleen and liver [4]. Because of the rarity of HSTCL, cases are unlikely to be identified in trials. Case reports leading to better understanding of Crohn's disease patients who experience HSTCL may help to identify those patients at increased risk. Causality assessment tools developed for case reports can then be used to determine the likelihood that a medication is causally associated with HSTCL.

We aimed to identify demographic and clinical characteristics and medication histories associated with HSTCL in Crohn's disease cases published in the peerreviewed literature or reported to the Food and Drug Administration (FDA) Adverse Event Reporting System (AERS) database. We used three different causality assessment tools to assess the strength of evidence supporting a causal relationship between medication exposures and HSTCL in Crohn's disease. This project was performed as part of a comparative effectiveness review of treatments for Crohn's disease [6]. We will also discuss the implications of our findings for the use of case reports in systematic reviews.

\section{Methods}

\section{Literature search and identification of cases from the published literature}

PubMed and Embase were queried on 25 January 2011 using predetermined search strings that included the terms 'Crohn's disease,' 'inflammatory bowel disease,' and 'hepatosplenic T cell lymphoma' (see full search strings in Additional file 1: Table S1). We included all study types with human patients. Studies were excluded if they were not written in English or if they did not include patients with Crohn's disease who had developed HSTCL. Additionally, all studies that met the inclusion criteria for the original systematic review were included if they specifically mentioned HSTCL. We also performed a hand-search of references in relevant articles. To avoid double counting of cases that had been reported multiple times in the literature, we checked the footnotes and references, as well as the demographic and clinical characteristics.

\section{Search of the Food and Drug Administration (FDA) Adverse Event Reporting System (AERS) database and identification of AERS cases}

The FDA AERS database was searched for all reported cases of HSTCL from January 2004, the first year data is available online, through December 2010. Only cases that had Crohn's disease listed as an indication for therapy were included. To avoid double counting of cases reported by multiple sources (such as by a treating physician and a pharmaceutical company), the case entries were matched by case number. If the case number did not match but the report had identical information for three of five criteria (age at diagnosis, date of death, diagnosis date, reporting country, sex), then this entry was reported as a unique case, similar to previous efforts to avoid duplicates using AERS [7].

\section{Matching cases from the published literature with AERS cases}

We sought to distinguish cases reported in both the published literature and AERS from those cases reported in only one source, using the following information: age at HSTCL diagnosis; date of HSTCL diagnosis or date of publication or AERS report when HSTCL date not reported; sex; medication history; reporting country (AERS) or country of origin (published literature); and date of death (AERS) or survival status or months of survival (published literature) (see Additional file 2: Table S2). If a case report from AERS and the literature matched on three of the five criteria, then the case was reported as a single unique case reported in both sources. We then identified cases reported 
in the published literature or AERS with sufficient information to consider them a unique case reported in only one source. Finally, some entries did not have sufficient details to determine if they were a unique case. We recorded the demographics of entries with insufficient reporting, but excluded the entries with insufficient reporting from the causality assessment.

\section{Causality assessment}

To evaluate the evidence supporting the association of medication exposures with HSTCL, we used causality assessment tools developed by the World Health Organization (WHO), Naranjo et al., and Kramer et al. [8-10]. Two evaluators (EC and SS) independently calculated the causality assessment score for each medication used in each case and then met to discuss and resolve by consensus differences between the scores.

Table 1 compares the characteristics and content of the three causality assessments. The Naranjo and Kramer assessments produced numerical scores that corresponded with causal categories of definite, probable, possible, and unlikely/doubtful. The WHO assessment assigns cases to the same categories as well as two additional categories of conditional/unclassified and unassessable/unclassifiable.

\section{Results}

\section{Search results and identification of unique cases}

Of the 123 citations identified by the PubMed and Embase searches, 19 case reports or case series [5,11-28] and three conference-presentation abstracts [29-31] met the inclusion criteria of reporting at least one Crohn's disease-related HSTCL case (Figure 1). Three additional conference-presentation abstracts were identified through a hand-search of the references of the included articles [32-34]. No comparative studies that met the inclusion criteria for the systematic review reported a case of HSTCL. One prospective study reported specifically that no cases of HSTCL were observed [35]. Thirty-four cases were identified from the published literature with 28 having sufficient information to be considered unique cases.

A search of the publicly available AERS data files yielded 139 patient identification numbers representing 50 unique case numbers, which after matching yielded 34 cases with 31 having sufficient information to be considered unique.

After matching unique cases from the published literature with the unique cases from AERS, 37 total cases were considered unique (22 from both sources, six from the published literature only, and nine from AERS only; Additional file 1: Table S1). Thirty-six HSTCL cases were considered unique based on age, sex, and medication exposures. An additional case was considered unique based on the case's use of cyclosporine even though age at HSTCL diagnosis and sex were not
Table 1 Characteristics of published instruments assessing causal relationship between medication exposure and adverse events

\begin{tabular}{|c|c|c|c|}
\hline & Naranjo & Kramer & WHO \\
\hline $\begin{array}{l}\text { Numerical } \\
\text { range }\end{array}$ & -4 to +13 & -7 to +7 & $\mathrm{n} / \mathrm{a}$ \\
\hline Format & $\begin{array}{l}\text { Ten questions } \\
\text { answered 'yes,' } \\
\text { 'no,' or 'don't } \\
\text { know,' each with } \\
\text { a numerical } \\
\text { value; numbers } \\
\text { summed for final } \\
\text { score. Higher } \\
\text { scores indicate } \\
\text { greater likelihood } \\
\text { of causality. }\end{array}$ & $\begin{array}{l}\text { An algorithm } \\
\text { with six } \\
\text { separate axes/ } \\
\text { flowcharts. Each } \\
\text { axis contributes } \\
\text { points to the } \\
\text { final score. } \\
\text { Higher scores } \\
\text { indicate greater } \\
\text { likelihood of } \\
\text { causality. }\end{array}$ & $\begin{array}{l}\text { Contains six } \\
\text { categories; the } \\
\text { user selects the } \\
\text { one for which } \\
\text { most criteria are } \\
\text { met. }\end{array}$ \\
\hline $\begin{array}{l}\text { Distinguishes } \\
\text { irreversible } \\
\text { adverse events } \\
\text { from other } \\
\text { adverse events? }\end{array}$ & No & Yes & No \\
\hline $\begin{array}{l}\text { Addresses } \\
\text { methods used } \\
\text { to confirm } \\
\text { adverse event? }\end{array}$ & Yes & No & No \\
\hline $\begin{array}{l}\text { Asks about } \\
\text { serum } \\
\text { medication } \\
\text { levels? }\end{array}$ & Yes & Yes & No \\
\hline $\begin{array}{l}\text { Considers prior } \\
\text { experience with } \\
\text { medication? }\end{array}$ & Yes & Yes & Yes \\
\hline $\begin{array}{l}\text { Considers } \\
\text { alternate } \\
\text { etiologies? }\end{array}$ & Yes & Yes & Yes \\
\hline $\begin{array}{l}\text { Questions } \\
\text { about } \\
\text { rechallenge? }\end{array}$ & Yes & Yes & Yes \\
\hline $\begin{array}{l}\text { Questions } \\
\text { about } \\
\text { dechallenge? }\end{array}$ & Yes & Yes & Yes \\
\hline
\end{tabular}

n/a, not applicable; WHO, World Health Organization.

reported [32]. Nine cases had insufficient reporting (Additional file 2: Table S2).

\section{Demographics, presenting symptoms and survival}

The 37 unique patients were young ( $84 \%$ of patients were younger than age 40 years) and male (86\%; Table 2). Patients had Crohn's disease for a mean of 10 years prior to their diagnosis of HSTCL (range: 4 to 35 years). All patients reporting any symptoms presented with hepatosplenomegaly or splenomegaly $(100 \%)$, and approximately one-half presented with fever (47\%) or cytopenia (58\%). The median length of survival among the 26 cases with information was 7 months (range: 5 days to 9.7 years). HSTCL resulted in death for $65 \%$ of patients. Survival was not reported for $30 \%$ of cases and two patients were alive at the time of the case 


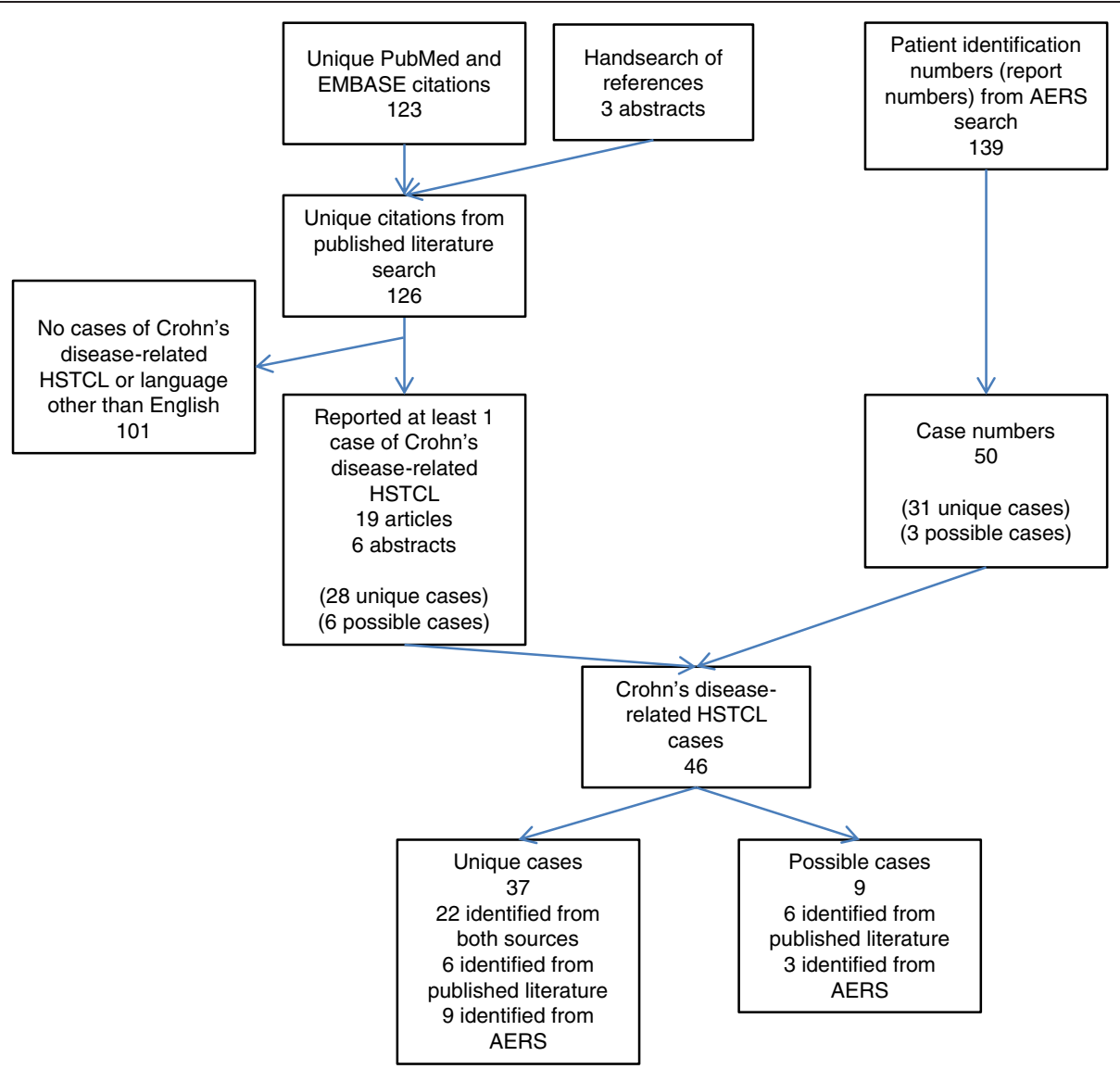

Figure 1 Identification of unique cases by PubMed and Embase searches. AERS, Adverse Event Reporting System; HSTCL, hepatosplenic T-cell lymphoma.

report: one patient at 3 months after receiving chemotherapy and a bone marrow transplant, and another patient at 20 months after HSTCL diagnosis.

Information about the patient's race, Crohn's disease location, behavior, and severity was infrequently reported in published case reports and case series. This information is not requested in the AERS case report form. Race was reported for two patients, both of whom were white $[15,25]$. Five patients had information on disease location: one patient had ileal disease [25], two patients had ileocolonic disease [12,17], one patient had ileal and perianal disease [15], and one patient had perianal disease [32]. Disease behavior was reported for one patient who had inflammatory disease [14].

\section{Medication history}

The timeline in Figure 2 displays the report of new HSTCL cases in patients with Crohn's disease from 1998 through 2010, including the 37 unique cases and the nine cases with insufficient information. Case exposure patterns for biologic medications were similar to the timeline of FDA approval for Crohn's disease: 96\% of biologic exposures among the 37 unique cases involved infliximab (approved in 1998), 29\% adalimumab (approved in 2007), $4 \%$ natalizumab (approved in 2008), $4 \%$ ustekinumab (not approved as of December 2012), and thus far no affected patients had certolizumab pegol exposure (approved in 2008). All cases that used a biologic had also used infliximab, with the exception of one case who used adalimumab only. The use of concurrent medications or medications at the time of HSTCL diagnosis cannot be summarized because this information was not uniformly reported.

The most frequently reported medications used were anti-metabolites and anti-TNFa agents (Table 3). Thirtysix unique cases (97\%) used an anti-metabolite and 28 cases (76\%) used an anti-TNFa. Eight cases had used an anti-metabolite without an anti-TNFa agent. One case had used cyclosporine and an anti-metabolite. Of the patients who used anti-TNFa therapy, 27 cases (96\%) had also used an anti-metabolite, but not necessarily at the same time. One patient who used anti-TNFa therapy 
Table 2 Demographic and clinical characteristics of reported Crohn's disease patients with hepatosplenic T-cell lymphoma (HSTCL)

\begin{tabular}{lcc}
\hline & $\begin{array}{c}\text { Unique cases } \\
(\mathbf{n}=\mathbf{3 7})\end{array}$ & $\begin{array}{c}\text { Cases with } \\
\text { insufficient } \\
\text { reporting } \\
\text { (n = 9) }\end{array}$ \\
\hline Age at HSTCL diagnosis, years & $\mathbf{n}=\mathbf{3 6}$ & $\mathbf{n}=\mathbf{0}$ \\
Mean & 30 & - \\
Median & 26 & - \\
Range & 12 to 79 & - \\
Disease duration, years & $\mathbf{n}=\mathbf{1 6}$ & $\mathbf{n}=\mathbf{0}$ \\
Mean & 10 & - \\
Median & 6 & - \\
Range & 4 to 35 & $\mathbf{n}=\mathbf{6}$ \\
Sex, $\mathbf{n}$ (\%) & $\mathbf{n}=\mathbf{3 6}$ & $1(17 \%)$ \\
Female & $5(14 \%)$ & $\mathbf{n}=\mathbf{4}$ \\
Survival, $\mathbf{n}$ (\%) & $\mathbf{n}=\mathbf{2 6}$ & $4(100 \%)$ \\
Died & $24(92 \%)$ & $0(0 \%)$ \\
Survived & $2(8 \%)$ & $\mathbf{n}=\mathbf{1}$ \\
Physical examination and laboratory & $\mathbf{n}=\mathbf{1 9}$ & - \\
abnormalities at time of \\
HSTCL diagnosis, $\mathbf{n}$ (\%)
\end{tabular}

Insufficient reporting on demographic information prevented us from identifying if the cases were unique. With each patient characteristic heading, the adjacent ' $n=x^{\prime}$ cells indicate the number of cases that reported on that particular demographic. The percentages calculated for sex, survival, and physical examination/laboratory abnormalities use this ' $\mathrm{n}$ ' as the denominator. HSTCL, hepatosplenic T-cell lymphoma, LDH, lactate dehydrogenase.

without anti-metabolites was reported in the AERS database. This patient had infliximab and adalimumab exposure (Additional file 2: Table S2).

Daily dose, duration, or cumulative dose of therapy were not consistently reported (Table 3 ). The majority of 'mean doses' were based on one to two patients. Infliximab was the only medication where measures of dose and duration were consistently provided. For the anti-metabolites, information on duration of treatment was also frequently provided, but information on daily or cumulative dose less so. Aminosalicylate and corticosteroid exposures were less commonly reported, despite the frequent use of aminosalicylates to treat colonic inflammatory disease and the use of corticosteroids to treat disease flares.

\section{Medication causality assessment}

Table 4 summarizes causality assessments based on the 37 unique cases. Using three causality assessment tools, the majority of medications received a score consistent with 'possible' cause. All three tools had criteria for rechallenge and dechallenge tests that could not be performed for an irreversible outcome like lymphoma, thus lowering the score. The tool of Kramer et al. included criteria for the incidence of HSTCL, which has not been estimated for Crohn's disease, thus lowering the score.

Scores calculated using the Naranjo method ranged from 1 to 2 points, corresponding with 'possible' causation (1 to 4 points) for each patient who used each medication. The items that contributed to the score for most patients included a point for administration prior to the development of HSTCL, and documentation of histopathology to confirm HSTCL diagnosis. All patients and medications lost one point because HSTCL has been reported in the absence of medications [5].

Scores calculated using the Kramer method did vary between medication classes. Anti-metabolites, biologics, and cyclosporine were determined to be a 'possible' cause of HSTCL (0 to 3 points). All other medications scored -1 point, determined to be an 'unlikely' cause ( $<0$ points). The variation in scores was due to previous reports of adverse reactions with the medication and availability of the medication. Anti-metabolites and cyclosporine were scored 0 points because they have been linked to other lymphomas. Natalizumab and ustekinumab were scored 0 points because they have been available for less than 20 years, so all adverse reactions have not yet been described. Anti-TNFa medications were scored 1 point because they have been associated with other lymphomas and have been available for less than 20 years. Antibiotics and corticosteroids received scores of -1 point because the medications have been available for long enough for most adverse reactions to have been previously reported and they have not been associated with lymphoma.

Assessments of causality using the WHO method provided determination of 'possible' causation. Because the time required for development of HSTCL is unknown, any medication administered before HSTCL diagnosis was considered to be within a 'reasonable' time period leading up to HSTCL development. Because HSTCL could have been explained by another medication or Crohn's disease itself, each medication used for each patient met the criterion for an alternative etiology.

\section{Discussion}

All medications were possibly related to HSTCL according to at least one causality assessment tool. Anti-metabolites, biologics, and cyclosporine were possibly related to HSTCL according to all three causality assessment tools. Despite the possible causal relationship found across three different tools for these medications, only the anti-TNFas carry a boxed warning for HSTCL. The label for azathioprine includes a boxed warning for malignancy with mention of 


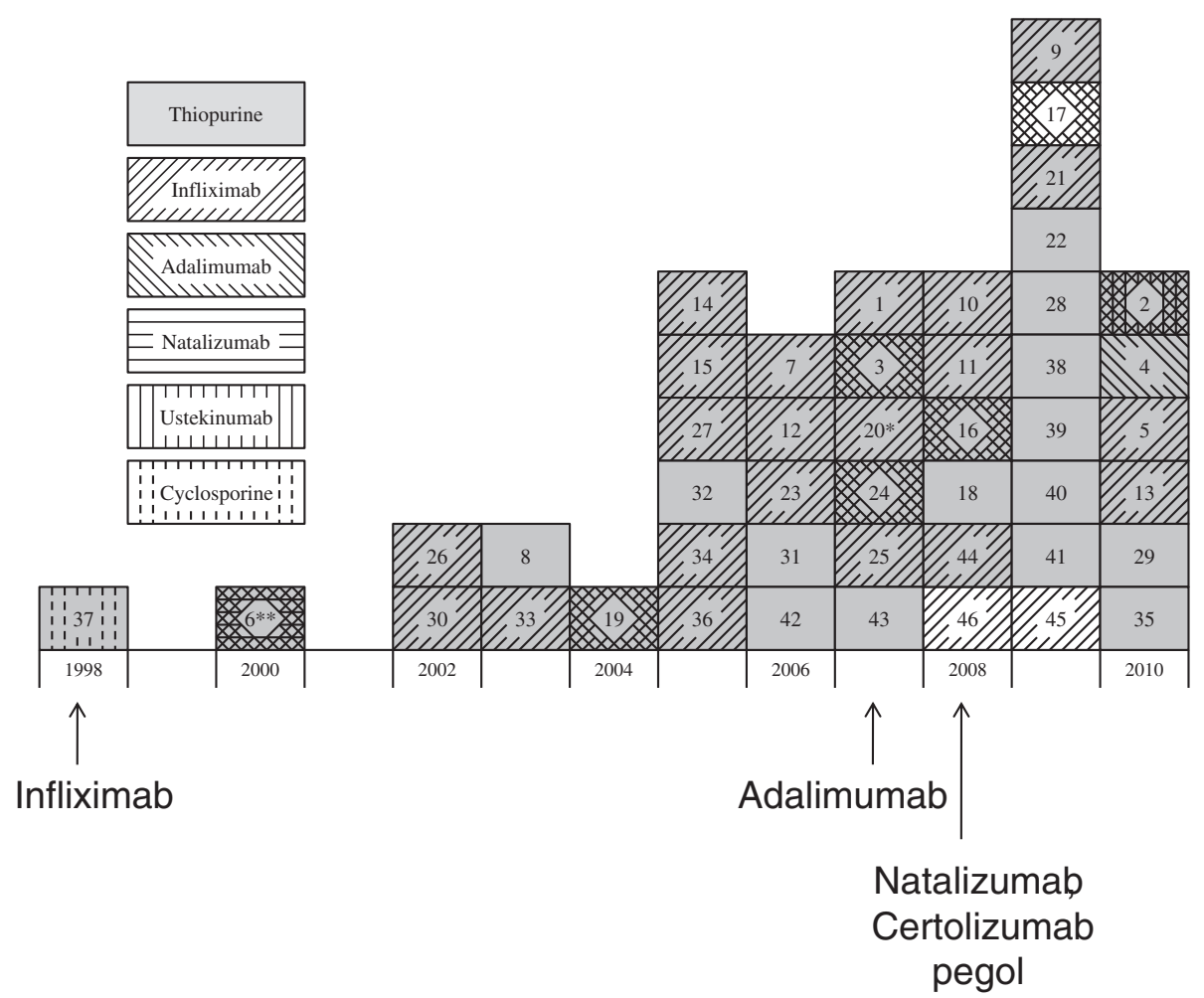

Figure 2 Timeline of medication approval by the Food and Drug Administration (FDA) and occurrence of hepatosplenic T-cell lymphoma (HSTCL). Includes 37 unique cases and nine cases with insufficient reporting, for a total of 46 cases. Each box includes a unique case by year the case was reported. The horizontal axis indicates the year the case was diagnosed. The numbers in each square are ordered oldest to youngest age at HSTCL diagnosis. They match up to the numbers with detailed case information in Additional file 2: Table S2. Vertical arrows indicate years that the particular medications were approved by the FDA. Ustekinumab is not approved by the FDA for Crohn's disease. The numbers within each box refer to case numbers in Additional file 2: Table S2. Patients were reported through 25 January 2011 (published) and December 2010 (AERS). *Date of case reported as 2007 to 2008. **Date of case reported as 2000 to 2009. AERS, Adverse Event Reporting System; FDA, Food and Drug Administration; HSTCL, hepatosplenic T-cell lymphoma.

HSTCL, and mercaptopurine's label mentions HSTCL in the non-boxed warnings. The label for cyclosporine mentions the risk of lymphoma in the boxed warnings, but not HSTCL specifically. The labels for natalizumab and ustekinumab do not mention lymphoma. The most common demographic risk factors were male sex and younger age, similar to previous studies [22,26,27]. No comparative study from the main systematic review included a case of HSTCL, and only one study specifically mentioned that no HSTCL cases were observed.

The methods guides for systematic reviews of the Evidence-based Practice Center (EPC) Program and the Cochrane Collaboration recommend using case series in some instances [36-38]. Based on the importance of HSTCL to patients, HSTCL's high mortality and the rarity of HSTCL, we performed a separate search of the published literature for HSTCL case reports and case series, and searched AERS as part of a systematic review for treatments of Crohn's disease. Our rationale for including cases is consistent with the recommendations of the methods guides. Other systematic reviews have included case reports and case series identified from the literature or cases from AERS based on similar rationale [39-43]. In contrast to many previous systematic reviews, we searched both case sources. Searching AERS yielded nine cases not identified in the published literature. However, because the majority of cases were identified in both AERS and the published literature, we had to create a process to identify the overlapping cases.

Insufficient reporting prevented us from determining the uniqueness of all identified cases. A few case reports failed to include patient age or sex. Many cases identified as unique did not include information on medication dose, frequency, or dates of use, even though reporting systems such the FDA AERS request this demographic and medication data on their submission forms [44]. Incomplete reporting is also prevalent in case reports on other types of adverse medication events, and calls have been made for a standardized list of case report guidelines similar to the checklists created by organizations for other types of observational studies [45]. Other agencies beside the FDA also request specific demographic, clinical, laboratory, and 
Table 3 Medications used to treat Crohn's disease prior to the diagnosis of hepatosplenic T-cell lymphoma (HSTCL) among unique cases

\begin{tabular}{|c|c|c|c|c|}
\hline Medication & $\begin{array}{l}\text { Number of cases } \\
\text { with exposure } \\
\text { reported, } n(\%) \\
(n=37)\end{array}$ & 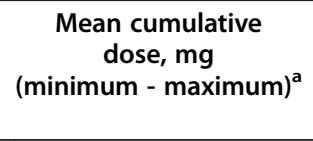 & $\begin{array}{c}\text { Mean duration of } \\
\text { use, years } \\
\text { (minimum - maximum) }^{\mathrm{a}}\end{array}$ & $\begin{array}{c}\text { Mean number of } \\
\text { infusions or injections } \\
\text { (minimum - maximum) }\end{array}$ \\
\hline Biologics & $28(76 \%)$ & & & \\
\hline \multirow[t]{2}{*}{ Adalimumab } & $8(22 \%)$ & $920(800$ to 1040$)$ & 1.5 (120 days to 2.6 years) & 11.5 (10 to 13$)$ \\
\hline & & $\mathrm{n}=2$ & $\mathrm{n}=2$ & $\mathrm{n}=2$ \\
\hline \multirow[t]{2}{*}{ Infliximab ${ }^{\mathbf{a}}$} & $27(73 \%)$ & $41(10$ to 120$) \mathrm{mg} / \mathrm{kg}$ & 1.8 (1 day to 6 years) & 9 (1 to 24$)$ \\
\hline & & $\mathrm{n}=7$ & $\mathrm{n}=12$ & $\mathrm{n}=17$ \\
\hline Natalizumab & $1(3 \%)$ & NR & NR & 3 \\
\hline Ustekinumab & $1(3 \%)$ & NR & NR & NR \\
\hline Certolizumab pegol & 0 & & & \\
\hline Anti-metabolites & $365(97 \%)$ & & & \\
\hline \multirow[t]{2}{*}{ 6-mercaptopurine } & $20(54 \%)$ & $94,508(3,900$ to 212,160$)$ & 4.8 (39 days to 8 years) & \\
\hline & & $\mathrm{n}=4$ & $\mathrm{n}=10$ & \\
\hline \multirow[t]{2}{*}{ Azathioprine } & $23(62 \%)$ & $192,108(1,450$ to 301,125$)$ & 5.8 (39 days to 13.5 years) & \\
\hline & & $\mathrm{n}=3$ & $\mathrm{n}=17$ & \\
\hline Aminosalicylates & $15(41 \%)$ & & & \\
\hline Balsalazide & $1(3 \%)$ & NR & NR & \\
\hline Mesalamine & $13(35 \%)$ & NR & $5(n=1)$ & \\
\hline Sulfasalazine & $2(5 \%)$ & NR & $10(n=1)$ & \\
\hline Corticosteroids & $22(59 \%)$ & & & \\
\hline Budesonide & $2(5 \%)$ & NR & NR & \\
\hline Hydrocortisone & $1(3 \%)$ & NR & NR & \\
\hline Prednisone & $14(38 \%)$ & NR & NR & \\
\hline Prednisolone & $5(14 \%)$ & NR & $13(n=1)$ & \\
\hline Corticosteroid & $4(11 \%)$ & NR & $10(n=1)$ & \\
\hline Other medications ${ }^{b}$ & $15(41 \%)$ & & & \\
\hline Antibiotics $^{c}$ & $8(22 \%)$ & NR & $N R$ & \\
\hline Cyclosporine & $1(3 \%)$ & NR & NR & \\
\hline
\end{tabular}

${ }^{a}$ Among those that reported this data. Cumulative dose excludes cases that only provided $\mathrm{mg} / \mathrm{kg}$ dosing but did not provide patient weight in kilograms and those cases which reported a daily dose but did not report duration of treatment. ${ }^{b}$ Excluding vitamin/mineral supplements. ${ }^{\text {CThe }}$ antibiotics used included ciprofloxacin, doxycycline, metronidazole, nitrofurantoin, and piperacillin/tazobactam. HSTCL, hepatosplenic T-cell lymphoma; NR, not reported.

medication information in adverse event reports [46]. Nevertheless, no standard checklist exists for case reporting, and journal requirements for case report content are variable [47].

The usefulness of case reports to identify potential adverse medication events will be enhanced by a standardized checklist for case reporting. Such a checklist should incorporate information commonly requested for adverse event reports and causality assessment, including: basic demographics, documentation of the use and timing of use of the individual and concomitant medications used to treat the condition (including absence of use), all other medications used by the patient, rechallenge and dechallenge information (including absence), laboratory results (including serum medication levels), and diagnostic tests used to confirm the adverse event. Reporting the complete list of medications used by the cases, rather than focusing on medications previously associated with the adverse events, as was common in the case reports we identified, will also aid in the understanding of drug interactions and the adverse event. Modifying the AERS database to require these elements for submission and standardizing the information in case reports submitted to journals will help to match AERS cases to the published cases, identify trends by items like race that are not consistently reported, and improve causality assessments. The suggested modifications are consistent with the Institute for Safe Medication Practices's (ISMP) recommendation to update AERS to improve the quality of reporting so that the FDA can make more targeted safety warnings $[48,49]$. 
Table 4 Results of the published instruments assessing causal relationship between medication exposure and adverse events when applied to patients in this case series

\begin{tabular}{|c|c|c|c|}
\hline Medication(s) & $\begin{array}{l}\text { Naranjo } \\
\text { score }\end{array}$ & $\begin{array}{l}\text { Kramer } \\
\text { score }\end{array}$ & $\begin{array}{l}\text { WHO } \\
\text { score }\end{array}$ \\
\hline \multicolumn{4}{|l|}{ Biologics } \\
\hline Adalimumab & Possible & Possible & Possible \\
\hline Certolizumab pegol & \multicolumn{3}{|c|}{ No use reported in any case report } \\
\hline Infliximab & Possible & Possible & Possible \\
\hline Natalizumab & Possible & Possible & Possible \\
\hline Ustekinumab & Possible & Possible & Possible \\
\hline \multicolumn{4}{|l|}{ Anti-metabolites } \\
\hline 6-mercaptopurine & Possible & Possible & Possible \\
\hline Azathioprine & Possible & Possible & Possible \\
\hline \multicolumn{4}{|l|}{ Aminosalicylates } \\
\hline Balsalazide & Possible & Unlikely & Possible \\
\hline Mesalamine & Possible & Unlikely & Possible \\
\hline Sulfasalazine & Possible & Unlikely & Possible \\
\hline \multicolumn{4}{|l|}{ Corticosteroids } \\
\hline Budesonide & Possible & Unlikely & Possible \\
\hline Hydrocortisone & Possible & Unlikely & Possible \\
\hline Prednisone & Possible & Unlikely & Possible \\
\hline Prednisolone & Possible & Unlikely & Possible \\
\hline Corticosteroid unspecified & Possible & Unlikely & Possible \\
\hline \multicolumn{4}{|l|}{ Other medications } \\
\hline Cyclosporine & Possible & Possible & Possible \\
\hline Metronidazole & Possible & Unlikely & Possible \\
\hline Nitrofurantoin & Possible & Unlikely & Possible \\
\hline Piperacillin/tazobactam & Possible & Unlikely & Possible \\
\hline Doxycycline & Possible & Unlikely & Possible \\
\hline Ciprofloxacin & Possible & Unlikely & Possible \\
\hline
\end{tabular}

Possible, all cases reporting that medication received a score of 'possible' using that particular causality assessment; unlikely, all cases reporting that medication received a score of 'unlikely' using that particular causality assessment. WHO, World Health Organization.

Using the causality assessment tools for an irreversible and almost uniformly fatal condition such as HSTCL was challenging. Based on available data, we could not make any causal assessments other than 'possible' for all medications. Some elements, such as rechallenge with medication, are not possible for events that rapidly progress to mortality. Improvement of symptoms for cancer with dechallenge is also rare, although regression of lymphoma with withdrawal of azathioprine has been documented [50]. Other items in the causality tools required more complete reporting, such as serum medication levels or details of the case confirmation, were not available for all cases. Better case reporting and understanding how to modify causality tools for use with irreversible adverse events will assist in making causality assessments for rare events from case reports. For events such as HSTCL that likely have a complex, multifactorial etiology that may develop over months to years, reporters should be prompted to include more detailed information on patient medical history (few of the reports had details on Crohn's disease severity and behavior), family history, and the absence of use or past use of certain medications commonly used to treat the underlying disease. This data could be requested as part of the FDA's existing enhanced safety surveillance of TNFa-blockers and pediatric and young adult malignancy, or even in routine submission of MedWatch forms for adverse events such as malignancy [51]. Journals can also request that authors provide this history when submitting case reports on malignancies that are possibly associated with medications. Routine reporting of this additional information may accelerate identification of other medications and risk factors associated with the adverse event. Causal assessments can then be modified to incorporate relevant biology and epidemiology and used to prioritize which safety events should be studied further to estimate a rate by medication use.

When possible causality has been established from case reports, trials and observational studies can contribute information to estimate a rate of disease by medication use. Trials and prospective studies may begin collecting information on safety events like HSTCL. If trials and observational studies report the occurrence of these rare events and details of the active or passive collection process, the rate of HSTCL can be estimated. For trials and comparative medication studies, a rate by medication use can be calculated by pooling the studies. Understanding the rate of disease, which is not possible from case reports, can help patients and their caretakers make better treatment decisions. Trials and observational studies should also attempt to collect specific details about the events. For example, the TREAT Registry, a Phase IV study for infliximab, reported a case of fatal peripheral T-cell lymphoma with infliximab and immunomodulator use within 6 months of death [52]. Readers cannot determine whether the T-cell lymphoma was HSTCL because details were not provided in the main text of the publication or the supplemental table. By providing more detailed information about the cause of death, particularly when a death may be due to a black box warning-related event, Phase IV studies could help to improve understanding of the rate of life-threatening events such as HSTCL in these important safety studies.

\section{Conclusions}

Consistent with FDA safety warnings, we confirmed that anti-metabolites, anti-TNFas, and cyclosporine have a possible causal association with HSTCL. We were unable to assign any score other than 'possible' 
using existing causality assessments because of limitations in data reported in case reports and difficulty in obtaining rechallenge and dechallenge data for a fatal event such as HSTCL. Minimum reporting requirements for peerreviewed literature and AERS will help facilitate the use of case reports to identify adverse events and assess causality. Reporting the absence of HSTCL in trials and cohort studies will provide information to estimate a rate of HSTCL occurrence by medication use. Intentional assessment will be particularly useful in studies that include children and young adults who appear to be at a greater risk of HSTCL. Our findings provide support for the development and adoption of case report guidelines, a topic that will be discussed at the next International Congress on Peer Review and Biomedical Publication [53]. Standards for collecting additional patient history in case reports and modifying causality assessment tools for irreversible events such as a fatal lymphoma will assist in making causal assessments using case reports.

\section{Additional files}

Additional file 1: Supplemental Table 1. Search strings used to

identify cases in PubMed and Embase.

Additional file 2: Supplemental Table 2. Case series: characteristics of individual cases identified in the literature and Adverse Event Reporting System.

\section{Abbreviations}

AERS: Adverse event reporting system; AHRQ: Agency for Healthcare Research and Quality; anti-TNFa: anti-tumor necrosis factor alpha; EPC: Evidence-based Practice Center; FDA: Food and Drug Administration; HSTCL: Hepatosplenic T-cell lymphoma; ISMP: Institute for Safe Medication Practices; NCRR: National Center for Research Resources; NIH: National Institutes of Health; WHO: World Health Organization.

\section{Competing interests}

The authors do not have any competing interests to declare.

\section{Authors' contributions}

SS and EC reviewed search results, performed data extraction and analysis, and applied the causality assessment tools. SS, EC, LW, and SH drafted the manuscript. EB was responsible for overseeing all work done on this project by the Evidence-based Practice Center (EPC) as part of its contract with the Agency for Healthcare Research and Quality (AHRQ). All authors contributed to the conception and design of the study, and read, revised, and approved the final manuscript.

\section{Acknowledgments}

This project was funded under contract number HHSA 290-2007-10061-I from the AHRQ, US Department of Health and Human Services. The authors of this article are responsible for its content, including any clinical treatment recommendations. No statement in this article should be construed as an official position of the AHRQ or of the US Department of Health and Human Services. SS was supported by the Johns Hopkins Predoctoral Clinical Research Training Program grant number 1TL1RR-025007 from the National Center for Research Resources (NCRR), a component of the National Institutes of Health (NIH). This article's contents are solely the responsibility of the authors and do not necessarily represent the official view of NCRR or $\mathrm{NIH}$. Publication of this article was funded in part by the Open Access Promotion Fund of the Johns Hopkins University Libraries.

\section{Author details}

'Johns Hopkins University School of Medicine, 733 North Broadway, Baltimore, MD 21205-2196, USA. Valley Medical Center, 400 South 43rd Street, Renton, WA 98055-5010, USA. ${ }^{3}$ Johns Hopkins University Bloomberg School of Public Health, 615 North Wolfe Street, Baltimore, MD 21205, USA. ${ }^{4}$ University of Maryland Medical Center, 22 South Greene Street, Room N3E09, Baltimore, MD 21201-1595, USA.

Received: 16 March 2013 Accepted: 24 June 2013

Published: 5 July 2013

\section{References}

1. Talley NJ, Abreu MT, Achkar JP, Bernstein CN, Dubinsky MC, Hanauer SB, Kane SV, Sandborn WJ, Ullman TA, Moayyedi P: An evidence-based systematic review on medical therapies for inflammatory bowel disease. Am J Gastroenterol 2011, 106(Suppl 1):2-25. quiz S26.

2. Korelitz BI, Present DH: A history of immunosuppressive drugs in the treatment of inflammatory bowel disease: origins at the Mount Sinai Hospital. Mt Sinai J Med 1996, 63:191-201.

3. Janssen Biotech, Inc: Highlights of prescribing information: Remicade (infliximab). Horsham, PA: Janssen Biotech, Inc; 2011. http://www.accessdata. fda.gov/drugsatfda_docs/label/2011/103772s5295/bl.pdf.

4. Armitage JO: The aggressive peripheral T-cell lymphomas: 2012 update on diagnosis, risk stratification, and management. Am J Hematol 2012, 87:511-519.

5. Falchook GS, Vega F, Dang NH, Samaniego F, Rodriguez MA, Champlin RE, Hosing C, Verstovsek S, Pro B: Hepatosplenic gamma-delta T-cell lymphoma: clinicopathological features and treatment. Ann Oncol 2009, 20:1080-1085.

6. Effective Health Care Program: Comparative effectiveness of pharmacologic therapies for the management of Crohn's disease. Rockville, MD: Agency for Healthcare Research and Quality; 2010. http://effectivehealthcare.ahrq.gov/ ehc/products/192/515/Crohns\%20Protocol\%2081\%2026\%2010.pdf.

7. Poluzzi E, Raschi E, Moretti U, De Ponti F: Drug-induced torsades de pointes: data mining of the public version of the FDA Adverse Event Reporting System (AERS). Pharmacoepidemiol Drug Saf 2009, 18:512-518.

8. Uppsala Monitoring Centre: The use of the WHO-UMC system for standardised case causality assessment. Uppsala: Uppsala Monitoring Centre. http://who-umc.org/Graphics/24734.pdf.

9. Naranjo CA, Busto U, Sellers EM, Sandor P, Ruiz I, Roberts EA, Janecek E, Domecq C, Greenblatt DJ: A method for estimating the probability of adverse drug reactions. Clin Pharmacol Ther 1981, 30:239-245.

10. Kramer MS, Leventhal JM, Hutchinson TA, Feinstein AR: An algorithm for the operational assessment of adverse drug reactions. I. Background, description, and instructions for use. JAMA 1979, 242:623-632.

11. Navarro JT, Ribera JM, Mate JL, Granada I, Junca J, Batlle M, Milla F, Feliu E: Hepatosplenic T-gammadelta lymphoma in a patient with Crohn's disease treated with azathioprine. Leuk Lymphoma 2003, 44:531-533.

12. Thayu M, Markowitz JE, Mamula P, Russo PA, Muinos WI, Baldassano RN: Hepatosplenic T-cell lymphoma in an adolescent patient after immunomodulator and biologic therapy for Crohn disease. J Pediatr Gastroenterol Nutr 2005, 40:220-222.

13. Kotlyar DS, Blonski W, Diamond RH, Wasik M, Lichtenstein GR: Hepatosplenic T-cell lymphoma in inflammatory bowel disease: a possible thiopurine-induced chromosomal abnormality. $\mathrm{Am} \mathrm{J}$ Gastroenterol 2010, 105:2299-2301.

14. Beigel F, Jurgens M, Tillack C, Subklewe M, Mayr D, Goke B, Brand S, Ochsenkuhn T: Hepatosplenic T-cell lymphoma in a patient with Crohn's disease. Nat Rev Gastroenterol Hepatol 2009, 6:433-436.

15. Drini M, Prichard PJ, Brown GJ, Macrae FA: Hepatosplenic T-cell lymphoma following infliximab therapy for Crohn's disease. Med J Aust 2008, 189:464-465.

16. He S, Roberts A, Ritchie D, Grigg A: Graft-versus-lymphoma effect in progressive hepatosplenic gamma/delta T-cell lymphoma. Leuk Lymphoma 2007, 48:1448-1450.

17. Humphreys MR, Cino M, Quirt I, Barth D, Kukreti V: Long-term survival in two patients with hepatosplenic $T$ cell lymphoma treated with interferon-alpha. Leuk Lymphoma 2008, 49:1420-1423.

18. Mackey AC, Green L, Leptak C, Avigan M: Hepatosplenic T cell lymphoma associated with infliximab use in young patients treated for 
inflammatory bowel disease: update. J Pediatr Gastroenterol Nutr 2009, 48:386-388.

19. Mackey AC, Green L, Liang LC, Dinndorf P, Avigan M: Hepatosplenic T cell lymphoma associated with infliximab use in young patients treated for inflammatory bowel disease. J Pediatr Gastroenterol Nutr 2007, 44:265-267.

20. Mittal S, Milner BJ, Johnston PW, Culligan DJ: A case of hepatosplenic gamma-delta T-cell lymphoma with a transient response to fludarabine and alemtuzumab. Eur J Haematol 2006, 76:531-534.

21. Moran G, Dillon J, Green J: Crohn's disease, hepatosplenic T-cell lymphoma and no biological therapy: are we barking up the wrong tree? Inflamm Bowel Dis 2009, 15:1281-1282.

22. Ochenrider MG, Patterson DJ, Aboulafia DM: Hepatosplenic T-cell lymphoma in a young man with Crohn's disease: case report and literature review. Clin Lymphoma Myeloma Leuk 2010, 10:144-148.

23. Rosh JR, Gross T, Mamula P, Griffiths A, Hyams J: Hepatosplenic T-cell lymphoma in adolescents and young adults with Crohn's disease: a cautionary tale? Inflamm Bowel Dis 2007, 13:1024-1030.

24. Shale M, Kanfer E, Panaccione R, Ghosh S: Hepatosplenic T cell lymphoma in inflammatory bowel disease. Gut 2008, 57:1639-1641

25. Zeidan A, Sham R, Shapiro J, Baratta A, Kouides P: Hepatosplenic T-cell lymphoma in a patient with Crohn's disease who received infliximab therapy. Leuk Lymphoma 2007, 48:1410-1413.

26. Kotlyar DS, Osterman MT, Diamond RH, Porter D, Blonski WC, Wasik M, Sampat S, Mendizabal M, Lin MV, Lichtenstein GR: A systematic review of factors that contribute to hepatosplenic T-cell lymphoma in patients with inflammatory bowel disease. Clin Gastroenterol Hepatol 2011, 9:36-41. e31.

27. Thai A, Prindiville T: Hepatosplenic T-cell lymphoma and inflammatory bowel disease. J Crohns Colitis 2010, 4:511-522.

28. Pozadzides JV, Pro B: Hepatosplenic T-cell lymphoma and TNF-alpha inhibitors. Expert Rev Hematol 2009, 2:611-614.

29. Grimpen F, Yeung D, Joseph J, Fay K, Buckland M, Talaulikar D, Elijah J, Clarke AC, Pavli P, Moore J: Hepatosplenic T cell lymphoma, immunosuppressive agents and biologicals: What are the risks? J Gastroenterol Hepatol 2009, 24:A314.

30. Kotlyar D, Blonski W, Mendizabal M, Lin MV, Lichtenstein GR: Case report of trisomy 13 in bone marrow in a case of hepatosplenic T-cell lymphoma (HSTCL) and inflammatory bowel disease (IBD). Gastroenterology 2009, 136:A146.

31. Kotlyar D, Blonski W, Porter DL, Mendizabal M, Lin MV, Lichtenstein GR: Hepatosplenic T-cell lymphoma (HSTCL) and inflammatory bowel disease (IBD): A rare complication after long-term thiopurine exposure: Case report and systematic review of the literature. Gastroenterology 2009, 136:A196-A197.

32. Lémann $M$, Gérard de La Valussière $F$, Carbonnel F, Bouhnik Y, Bonnet J, Allez M, Matuchansky C, Cosnes J, Jian R, Rambaud JC, Gendre JP, Modigliani R: Intravenous cyclosporine for perianal Crohn's disease (CD). Gastroenterology 1998, 114:A1020

33. Falchook GS, Champlin R, Hagemeister FB, Hosing C, Kwak LW, O'Brien S, Rodriguez MA, Verstovsek S, Pro B: Hepatosplenic T-cell lymphoma: clinical characteristics and treatment outcome. ASH Annual, Meeting Abstracts 2006, 108:2460

34. Fowler S, Beyak M, Depew WT, Justinich C, Ropeleski MJ: W1212 hepatosplenic T-cell lymphoma in Crohn's disease. Where does the risk lie? Gastroenterology 2010, 138:675.

35. Beaugerie L, Brousse N, Bouvier AM, Colombel JF, Lémann M, Cosnes J, Hébuterne X, Cortot A, Bouhnik Y, Gendre JP, Simon T, Maynadié M, Hermine O, Faivre J, Carrat F, CESAME Study Group: Lymphoproliferative disorders in patients receiving thiopurines for inflammatory bowel disease: a prospective observational cohort study. Lancet 2009, 374:1617-1625.

36. Chou R, Aronson N, Atkins D, Ismaila AS, Santaguida P, Smith DH, Whitlock E, Wilt TJ, Moher D: AHRQ series paper 4: assessing harms when comparing medical interventions: AHRQ and the effective health-care program. J Clin Epidemiol 2010, 63:502-512.

37. Agency for Healthcare Research and Quality: Methods guide for medical test reviews. Rockville, MD: Agency for Healthcare Research and Quality; 2010. http://effectivehealthcare.ahrq.gov.

38. Higgins JPT, Green S (Eds): Cochrane handbook for systematic reviews of interventions. Version 5.1.0 (updated March 2011). Oxford: The Cochrane Collaboration; 2011. http://www.cochrane-handbook.org.

39. Jefferson $T$, Jones $M$, Doshi $P$, Del Mar C: Neuraminidase inhibitors for preventing and treating influenza in healthy adults: systematic review and meta-analysis. BMJ 2009, 339:5106.
40. Bybee KA, Kara T, Prasad A, Lerman A, Barsness GW, Wright RS, Rihal CS: Systematic review: transient left ventricular apical ballooning: a syndrome that mimics ST-segment elevation myocardial infarction. Ann Intern Med 2004, 141:858-865.

41. Effective Health Care Program: Evidence-based practice center systematic review protocol pressure ulcer treatment strategies: A comparative effectiveness review. Rockville, MD: Agency for Healthcare Research and Quality; 2011. http://effectivehealthcare.ahrq.gov/ehc/products/308/838/Pressure-UlcerTreatment_\%20Protocol_20111108.pdf.

42. Reeves BC, Vardulaki KA, Tsang VTC, Bennett-Lloyd BD, O'Riordan PA: A systematic review of case series of paediatric cardiac surgery [abstract]. Cape Town: 8th Annual Cochrane Colloquium; 2000. http://cmr.cochrane.org/? CRGReportID=2998.

43. Gartlehner G, Hansen RA, Jonas BL, Thieda P, Lohr KN: The comparative efficacy and safety of biologics for the treatment of rheumatoid arthritis: a systematic review and metaanalysis. J Rheumatol 2006, 33:2398-2408.

44. US Food and Drug Administration: The FDA Safety Information and Adverse Event Reporting Program. MedWatch 3500 form. Silver Spring, MD: US Food and Drug Administration; 2013. http://www.fda.gov/downloads/AboutFDA/ ReportsManualsForms/Forms/UCM163919.pdf.

45. Aronson JK: Anecdotes as evidence. BMJ 2003, 326:1346.

46. National Institute of Diabetes and Digestive and Kidney Diseases: Important elements to include in reporting cases of drug-induced liver injury. Bethesda, MD: National Institute of Diabetes and Digestive and Kidney Diseases; 2013. http://livertox.niddk.nih.gov/ImportantElements.aspx.

47. Sorinola O, Olufowobi O, Coomarasamy A, Khan KS: Instructions to authors for case reporting are limited: a review of a core journal list. BMC Med Educ 2004, 4:4

48. Institute for Safe Medication Practices: QuarterWatch: Monitoring FDA MedWatch reports: Signals for dabigatran and metoclopramide. Horsham, PA: Institute for Safe Medication Practices; 2012. http://www.ismp.org/ quarterwatch/pdfs/2011Q1.pdf.

49. Moore TJ, Singh S, Furberg CD: The FDA and new safety warnings. Arch Intern Med 2012, 172:78-80.

50. Larvol L, Soule JC, Le Tourneau A: Reversible lymphoma in the setting of azathioprine therapy for Crohn's disease. N Engl J Med 1994, 331:883-884.

51. US Food and Drug Administration: FDA drug safety communication: Update on tumor necrosis factor (TNF) blockers and risk for pediatric malignancy. Silver Spring, MD: US Food and Drug Administration; 2013. http://www.fda. gov/Drugs/DrugSafety/ucm278267.htm.

52. Lichtenstein GR, Feagan BG, Cohen RD, Salzberg BA, Diamond RH, Chen DM, Pritchard ML, Sandborn WJ: Serious infections and mortality in association with therapies for Crohn's disease: TREAT registry. Clin Gastro and Hepatol 2006, 4:621-630.

53. International Congress on Peer Review and Biomedical Publication: The Seventh International Congress on Peer Review and Biomedical

Publication, September 8-10, 2013. Chicago, IL: JAMA and London: BMJ; 2013. http://www.peerreviewcongress.org/preliminary-program.html.

\section{doi:10.1186/2046-4053-2-53}

Cite this article as: Selvaraj et al:: Use of case reports and the Adverse Event Reporting System in systematic reviews: overcoming barriers to assess the link between Crohn's disease medications and hepatosplenic T-cell lymphoma. Systematic Reviews 2013 2:53.

\section{Submit your next manuscript to BioMed Central and take full advantage of:}

- Convenient online submission

- Thorough peer review

- No space constraints or color figure charges

- Immediate publication on acceptance

- Inclusion in PubMed, CAS, Scopus and Google Scholar

- Research which is freely available for redistribution 